\title{
Evaluation of the Efficacy of Liposomal Bupivacaine Infiltrated into the Posterior Capsule for Postoperative Analgesia after Total Knee Arthroplasty-A Randomized Double Blind Clinical Trial
}

\author{
Mohit Garg1, Piyush Gupta1, Kevin Kang2, Avichai Dukshtein1, Dennis Feierman1 \\ ${ }^{1}$ Department of Anesthesiology, Maimonides Medical Center, Brooklyn, NY, USA \\ ${ }^{2}$ Department of Orthopedics, Maimonides Medical Center, Brooklyn, NY, USA \\ Email: dfeierman@maimonidesmed.org
}

How to cite this paper: Garg, M., Gupta, P., Kang, K., Dukshtein, A. and Feierman, D. (2017) Evaluation of the Efficacy of Liposomal Bupivacaine Infiltrated into the Posterior Capsule for Postoperative Analgesia after Total Knee Arthroplasty-A Randomized Double Blind Clinical Trial. Open Journal of Anesthesiology, 7, 381-392. https://doi.org/10.4236/ojanes.2017.711039

Received: August 15, 2017

Accepted: November 26, 2017

Published: November 29, 2017

Copyright $\odot 2017$ by authors and Scientific Research Publishing Inc. This work is licensed under the Creative Commons Attribution International License (CC BY 4.0).

http://creativecommons.org/licenses/by/4.0/

\section{(c) (i) Open Access}

\begin{abstract}
Achieving adequate control of postsurgical pain remains a challenge in patients undergoing Total Knee Arthroplasty (TKA). The objective of this study was to assess if liposomal bupivacaine injected into the posterior capsule, in combination with a femoral nerve block and multimodal pain control regimen, would result in better pain control. The two groups were similar with regards to demographics and method of intraoperative anesthesia. Infiltration into the posterior capsule with liposomal bupivacaine had significantly lower resting pain scores compared to the saline group. Patients in the liposomal bupivacaine group also used slightly less breakthrough narcotic (5.75 to 4.31 $\mathrm{mg}$ of morphine equivalence). We recommend the use of infiltration of liposomal bupivacaine into the posterior capsule as an adjunct in multimodal analgesia in TKA patients to reduce pain and resultant narcotic use.
\end{abstract}

Keywords

Liposomal Bupivacaine, Exparel, Knee Arthroplasty

\section{Introduction}

Total knee arthroplasty (TKA) is often undertaken in patients with end-stage knee arthritis. Although TKA can be a very successful procedure, results from patient surveys suggest there can be a high incidence of moderate to severe post-surgical pain [1] [2]. The number of knee arthroplasties performed in the 
United States has doubled in the last decade. However, acute pain management remains a challenge [3] [4] [5]. Poor pain control has an established relationship with delays in rehabilitation, prolonged hospital stays and the potential of progression to chronic pain [6]. Furthermore, the Joint Commission on Accreditation of Healthcare Organization (JCAHO) has endorsed comprehensive assessment and adequate treatment of post-operative pain by developing standardized guidelines [7].

In order to achieve optimal pain relief after TKA, several modalities have been studied including femoral nerve block, intra-articular/peri-articular injection of local anesthetics, opioids, non-steroidal anti-inflammatory drugs (NSAIDs, cyclooxygenase (cox) inhibitors), as well as epidural analgesia [8] [9] [10] [11] [12]. Currently, multimodal pain management techniques are the standard of care. These include administration of two or more drugs that have different mechanism of action with a goal to decrease the use of opioids and their sequelae [6] [13] [14] [15].

\section{Study Design}

The study is single center, placebo controlled, double blinded, randomized control trial. After IRB approval and registration of the clinical trial at clinicaltrials.gov (NCT02011464), 20 patients consented to participate in the study. The study included patients with primary osteoarthritis undergoing total knee arthroplasty either under spinal or general anesthesia.

The patients were randomly distributed into two groups with Group A (control) receiving $20 \mathrm{ml}$ of normal saline (0.9\%) while Group B (study) received 20 $\mathrm{ml}$ of liposomal bupivacaine injected into the posterior capsule during TKA by the orthopedic surgeons. The preoperative history and physical was used as our screening tool to ensure that the participant had the require inclusion criteria and none of the exclusion criteria. If the screening showed that they could participate, the study team would consent them for the study. Twenty numbered envelopes were created. Each envelope had a card that was generated with a randomization program that had the restriction that there would be 10 participants in each group placing the patient in their respective group. Patients from both groups received a femoral nerve block with catheter placement for continuous infusion of local anesthetic. The infusion rate was maintained at $6-8$ $\mathrm{cc} /$ hour of $0.1 \%$ Ropivacaine. Multimodal analgesia was used to supplement pain control, which included Tylenol P.O. $1 \mathrm{~g}$ TID (not to exceed $4 \mathrm{~g}$ in 24 hours), Oxy Contin $10 \mathrm{mg}$ PO BID, and Celebrex $200 \mathrm{mg}$ PO daily. All patients had access to both oral and intravenous rescue narcotic analgesics after surgery. The time, day and number of requests for breakthrough (additional) analgesia were recorded. Pain scores were assessed using an 11-point (0 - 10) numeric rating scale-(NRS). Pain was assessed for both posterior and anterior aspects of the knee when at rest for the following intervals: post anesthesia care unit (PACU) arrival, $4,8,12,24,48$, and 72 hours after the posterior injection. Pain with knee 
range of motion was also noted.

\section{Objectives}

1) Assess the efficacy of pain control of liposomal bupivacaine when injected into the posterior knee capsule along with femoral nerve block after total knee arthroplasty.

2) Record and assess the date, time, amount and route of all opioid analgesics administered for breakthrough pain.

3) Assess pain levels during knee range of motion.

4) Incidence of opioid related side effects (nausea, vomiting, constipation, respiratory depression and hypoxia) or adverse events.

\section{Patients}

Inclusion criteria:

- Males and females age range 18 - 75 years with planned TKA.

- ASA physical classification status 1 - 3 .

- Patients must be physically and mentally able to participate in the study and complete all study assessments.

- Patients must be able to give informed consent to participate in this study after demonstrating a good understanding of the risks and benefits of the proposed components of infiltration into the posterior capsule of the knee.

Exclusion criteria:

- History of hypersensitivity or idiosyncratic reactions to amide-type local anesthetics.

- Any patient whose anatomy or surgical procedure, in the opinion of the investigator, might preclude the potential successful performance of an appropriate liposomal bupivacaine infiltration into the posterior capsule of the knee.

- Any patient, who in the opinion of the investigator, might be harmed or be a poor candidate for participation in the study.

- Any patient, who in the opinion of the investigator, is on chronic pain medicine (opioids), or large doses of NSAIDs.

- Patients who have received any investigational drug within 30 days prior to study drug administration, or planned administration of another investigational product or procedure during their participation in the study.

- History of pre-existing neurological disorders/neuropathy.

\section{Statistical Methods}

Assuming a difference of at least three points on an eleven-point pain scale from 0 to $10 \mathrm{NRS}$ pain scale and a standard deviation $(\mathrm{SD}=2.2[16])$, the effect size is expected to be at least 1.36 with a sample of 10 in each group (Group A and Group B) that should provide $82 \%$ power to detect a significant difference with alpha $=0.05$. The time course of mean pain scores from 4 to 72 hours postopera- 
tively was analyzed using mixed model regression.

We compared both the individual post-surgical breakthrough narcotic used and the total breakthrough narcotic use. For the total breakthrough use, the dose of all opioids administered was converted into morphine equivalents for the analysis. The morphine equivalents were calculated by converting the oxycodone (per oral, PO), morphine (intravenous, IV) and hydromorphone (IV) by dividing by 2,1 and 0.16 respectively (for example $20 \mathrm{mg}$ of oxycodone $=10 \mathrm{mg}$ morphine and $1.6 \mathrm{mg}$ of hydromorphone $=10 \mathrm{mg}$ of morphine equivalent) [17]. Duration of analgesia observed with liposomal bupivacaine was compared with controls receiving placebo ( $0.9 \%$ normal saline). Additionally, the incidence of postsurgical adverse effects was noted.

\section{Results}

The demographics of the two groups are shown in Table 1 . There were more females in the control group $(\mathrm{N}=8,80 \%)$ compared to study group $(\mathrm{N}=6$, $60 \%)$. This was secondary to the small group size and tried to consecutively consent anyone that made the criteria to be included in the study. However, there was no significant difference in sex, age, weight, height, BMI or ASA status between the two groups. The mean operative time in the Liposomal bupivacaine group was $2.01 \pm 0.4 \mathrm{hrs}$ versus $1.97 \pm 0.7 \mathrm{hrs}$ in the control group with no significant difference between the two $(\mathrm{p}=0.44)$. The majority of patients $(\mathrm{N}=9$, $90 \%$ in each group) received spinal anesthesia with a propofol infusion for sedation. The remaining patients underwent general anesthesia for the procedure. All patients received a continuous femoral nerve block with an indwelling catheter as well. The control group received more intraoperative fentanyl than the bupivacaine group, but was not found to be statistically significant $(145 \mathrm{mcg}$ vs. $95 \mathrm{mcg}$ of fentanyl for control group and liposomal bupivacaine groups, respectively $[\mathrm{p}=0.12])$.

Table 1. Characteristics of study population.

\begin{tabular}{ccccc}
\hline S. No & Variable & Control population $\mathbf{N}=10(100 \%)$ & Study group $\mathbf{N}=10(100 \%)$ & P value \\
\hline & Gender & & & \\
1. & Male & 2 & 6 & 0.63 \\
& Female & 8 & $66.1 \pm 4.7(68-63=5)$ & 0.14 \\
2. & Age (IQR) & $62.8 \pm 6.0(66-57=9)$ & $82.9 \pm 14.7$ & 0.36 \\
& Weight Height & $78.2 \pm 12.4$ & $66.1 \pm 8.5$ & 0.25 \\
3. & BMI & $64.4 \pm 6.0$ & $33.7 \pm 5.9$ & 0.36 \\
& & $32.6 \pm 3.7$ & $2.7 \pm 0.7$ & 0.5 \\
\hline
\end{tabular}

Demographic characteristics of both groups: Control group received a saline injection whereas the study group received $20 \mathrm{ml}$ of Liposomal bupivacaine (Exparel) in the posterior knee compartment. BMI = Body Mass Index; ASA = The American Society of Anesthesiologists (ASA) Physical Status classification system. 
Table 2. Postoperative narcotic use.

\begin{tabular}{cccc}
\hline Groups & Control population $\mathbf{N}=10$ & Study Population $\mathbf{N}=10$ & P Value \\
\hline Oxycodone & $8.00 \pm 4.22$ & $7.00 \pm 3.50$ & 0.57 \\
Morphine & $0.50 \pm 1.05$ & $0.50 \pm 1.05$ & 0.99 \\
Hydromorphone & $0.20 \pm 0.35$ & $0.05 \pm 0.16$ & 0.15 \\
Morphine Equivalent & $5.75 \pm 3.63$ & $4.31 \pm 2.4$ & 0.31 \\
\hline
\end{tabular}

Narcotic consumption of both groups: (overall narcotic consumption was covert to morphine equivalents' for comparison using a student-t test). Control group received a saline injection whereas the study group received $20 \mathrm{ml}$ of Liposomal bupivacaine (Exparel) in the posterior knee compartment.

Pain scores:

Pain scores for the posterior aspect of the knee were lower at all time points in the liposomal bupivacaine group compared to the control group as shown in Figure 1 . The difference was statistically significant after $8 \mathrm{hrs}$ post op. Interestingly, although not statistically significant, patients in the control group reported lower pain scores in the anterior knee at rest at all time points (Figure 2).

In the control group, pain scores for the anterior portion of the knee were significantly lower compared to posterior knee scores (Figure 3). There was no statistically significant difference between the anterior and posterior knee pain scores within the liposomal bupivacaine group (Figure 4).

All patients were able to ambulate after TKA without any significant quadriceps weakness or episodes of falls after the surgery. However, it was difficult to distinguish between anterior and posterior pain on movement of the knee joint. Therefore, data was incomplete and could not be analyzed.

Narcotic dose requirement:

Patients in the study group had lower opioid requirement up to 72 hours postoperatively. However, there was not a significant difference for the use of breakthrough narcotics. The calculated morphine equivalents in the control group were $5.75 \pm 3.63$ (mean $\pm \mathrm{SD}$ ) versus $4.31 \pm 2.40$ (mean $\pm \mathrm{SD}$ ) in the study group, $[\mathrm{p}=0.31]$ (Table 2$)$.

\section{Discussion}

The major drawback of local infiltration anesthesia is their short duration of action. Bupivacaine is one of the long acting local infiltration agents with its effect lasting 12 hours or less [18]. Extended release liposomal bupivacaine, Exparel (Pacira, Parsippany, NJ) is a suspension of multivesicular liposomes which release bupivacaine over several days prolonging its analgesic effect for over 72 hours [19].

In our placebo controlled, double-blinded, randomized controlled trial (RCT), Figure 3 shows that, without liposomal bupivacaine (the control group), posterior knee pain was significantly higher than the anterior knee pain since anterior knee pain was diminished by the femoral nerve block. Administration of liposomal bupivacaine did significantly reduce posterior knee pain significantly as 


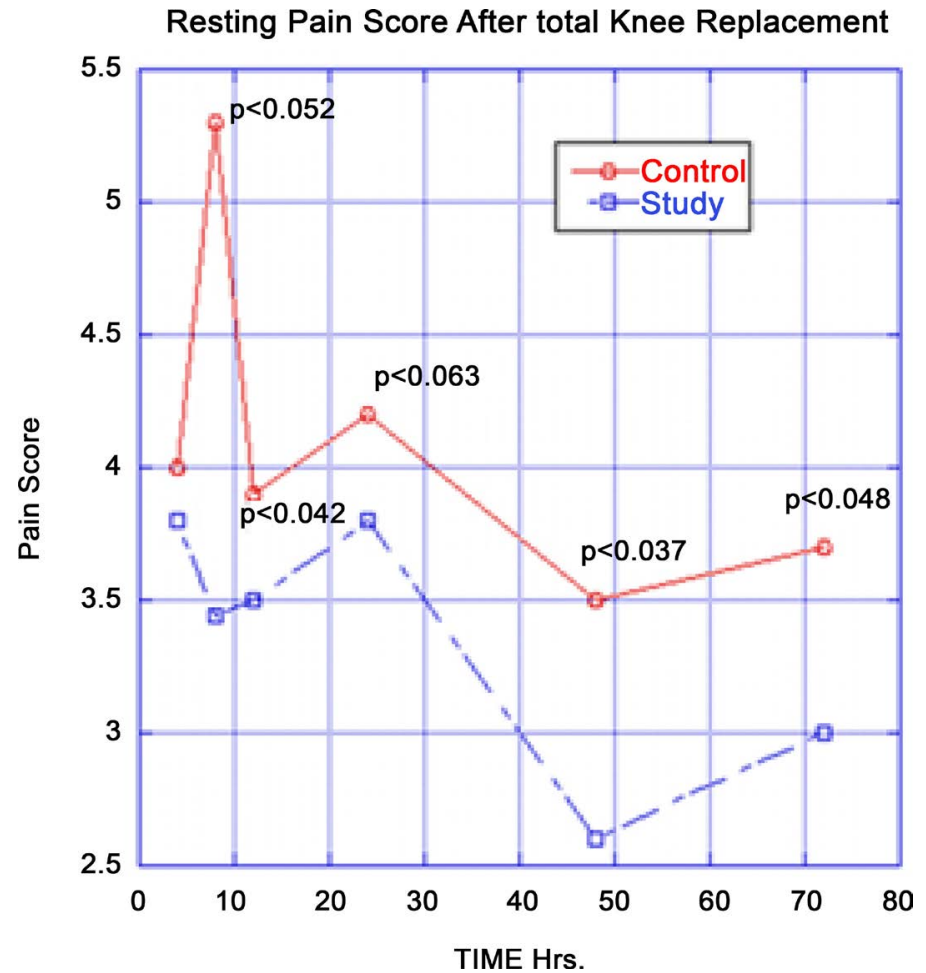

Figure 1. Patient were asked about the posterior knee pain score at 4, 8, 12, 24, 48 and 72 hrs. Control group received a saline injection whereas the study group received $20 \mathrm{ml}$ of Liposomal bupivacaine (Exparel) in the posterior knee compartment. Both groups receive a continuous femoral nerve block infusion.

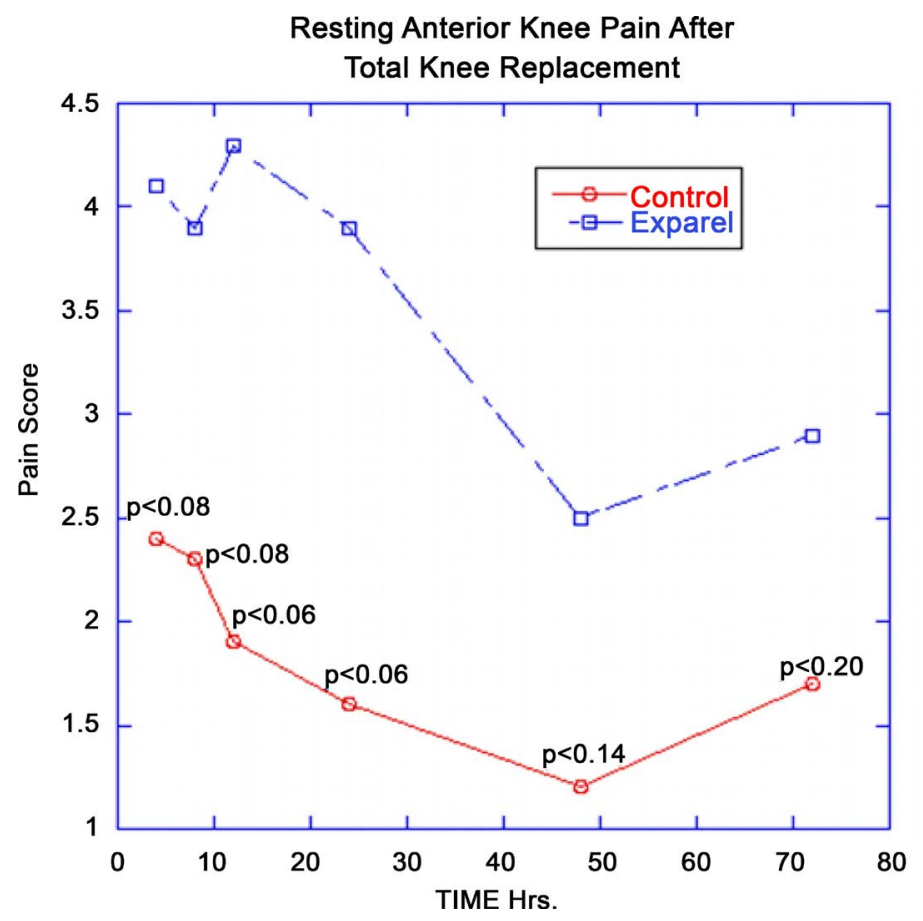

Figure 2. Patients were asked about the anterior knee pain score at 4, 8, 12, 24, 48 and 72 hrs. Control group received a saline injection whereas the study group received $20 \mathrm{ml}$ of Liposomal bupivacaine (Exparel) in the posterior knee compartment. Both groups receive a continuous femoral nerve block infusion. 


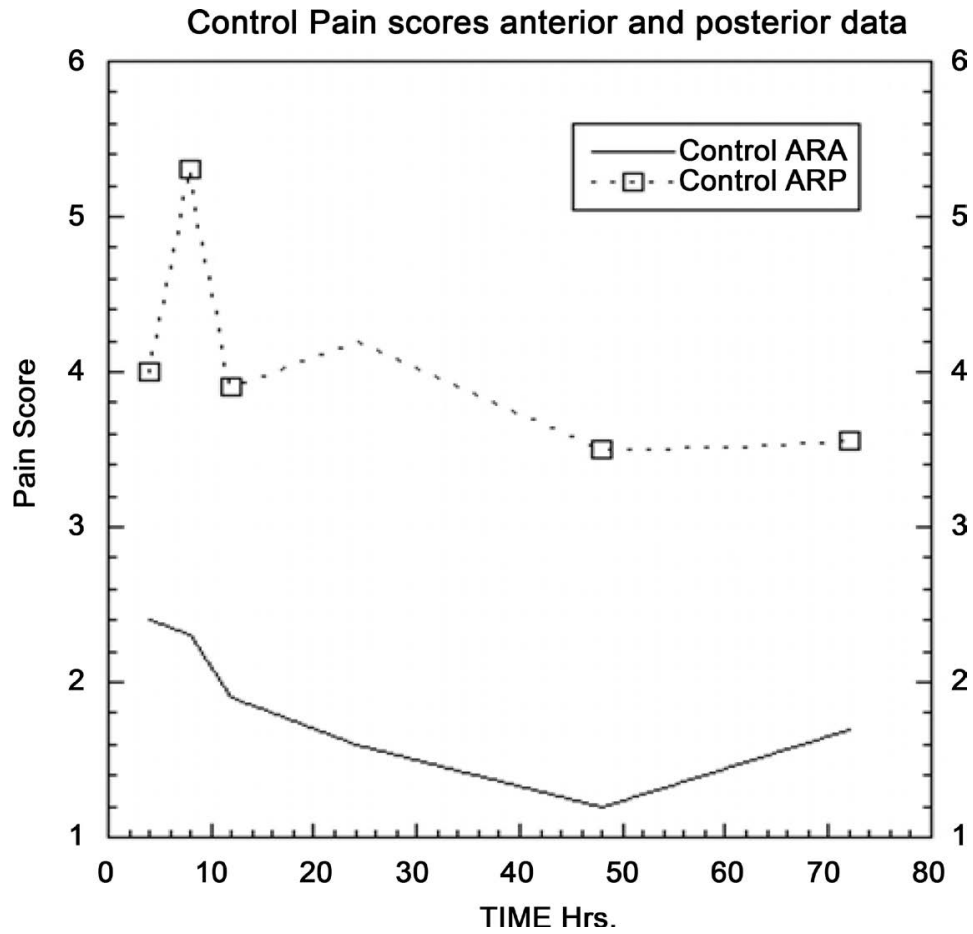

Figure 3. Patients in the control group were asked about the anterior and posterior knee pain scores at $4,8,12,24,48$ and $72 \mathrm{hrs}$. Patients receive a continuous femoral nerve block infusion. $\mathrm{ARA}=$ at rest anterior pain; $\mathrm{ARP}=$ at rest posterior pain. $\mathrm{P}<0.12, \mathrm{P}<$ $0.016, \mathrm{P}<0.046, \mathrm{P}<0.023$. $\mathrm{P}<0.043$ and $\mathrm{P}<0.128$ at $4,812,24,48,72 \mathrm{hrs}$, respectively.

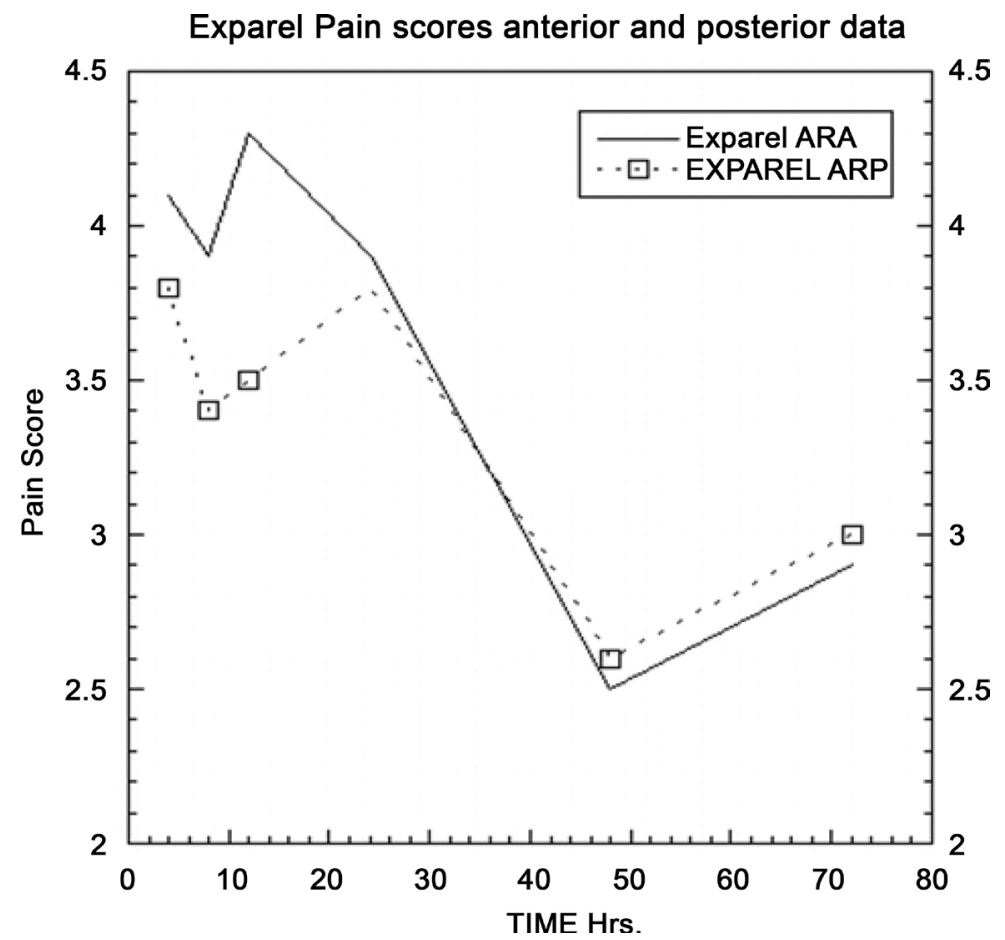

Figure 4. Patient in the Exparel group were asked about the anterior and posterior knee pain scores at 4, 8, 12, 24, 48 and $72 \mathrm{hrs}$. Patients also receive a continuous femoral nerve block infusion. There was little difference between anterior and posterior pain. ARA = at rest anterior pain; $\mathrm{ARP}=$ at rest posterior pain. 
compared to periarticular injection of normal saline (Figure 1). In fact, Figure 4 shows that when the posterior capsule is injected with liposomal bupivacaine and a femoral nerve block was used for anterior knee pain the patients felt little difference between anterior and posterior knee pain.

Interestingly the pain scores on the anterior aspect of the knee were higher in the liposomal bupivacaine group compared to the control group (Figure 2). This could also be explained by better pain control on posterior aspect of knee in liposomal bupivacaine group thus leading to a relatively increased pain perception on anterior aspect of knee. Most of the available RCT in the literature have drawn comparisons between liposomal bupivacaine and bupivacaine $\mathrm{HCl}$ for pain control as local analgesic infiltration after TKA [20]-[29]. However, there is paucity of data for analgesic efficacy of liposomal bupivacaine in placebo controlled, randomized trial as part of multimodal analgesia.

The randomized trial from Schroer et al. [20] and Alijanipour et al. [21] showed no difference in pain scores between local infiltration of liposomal bupivacaine versus bupivacaine $\mathrm{HCl}$ after TKA. In another RCT from Bramlett et al. [22] plasma concentrations of bupivacaine in blood samples of patients were measured along with pain scores. The results demonstrated statistically significant reduction in pain scores with liposomal bupivacaine in their high dosage group of $532 \mathrm{mg}$ compared to bupivacaine $\mathrm{HCl}$ at a dosage of $150 \mathrm{mg}$ after TKA. However, there was no statistical significant difference in pain scores in liposomal bupivacaine with dosages $133 \mathrm{mg}, 266 \mathrm{mg}$ and $399 \mathrm{mg}$ compared to bupivacaine HCL group at a dosage of $150 \mathrm{mg}$. Studies reviewed here support the results demonstrated in this study showing decreased pain scores in the liposomal group.

In a recent RCT, Collis et al. [23] compared liposomal bupivacaine injection with a mixture of ropivacaine, epinephrine, ketorolac and clonidine. Collis et al. found similar pain scores in two groups with no difference in the postoperative narcotic use between the two groups. In another similar RCT comparing periarticular injection of liposomal bupivacaine to combination of ropivacaine, clonidine, toradol, epinephrine and saline after TKA, Schwarzkopf et al [24] demonstrated no significant difference in daily postoperative narcotic use between the two groups. Bagsby et al. [25] in a retrospective study found contradictory results to the above two RCT with higher opiate consumption in patients injected with liposomal bupivacaine in comparison to periarticular injection mixture consisting of ropivacaine, morphine and epinephrine. Schroer et al. [20] demonstrated similar narcotic requirements in liposomal bupivacaine group compared to bupivacaine $\mathrm{HCl}$ group in postoperative period after TKA. We found similar results in this study with lower narcotic consumption in the liposomal group, but the difference did not reach statistical significance.

There are many strengths of this study. All measures were taken to eliminate confounding factors between two groups prior to randomization. Patients on chronic opioids were excluded to prevent skewing of results. This is a double 
blinded study as both patient and investigator were unaware of patient's actual treatment. In other studies where the surgeon is an investigator, double blinding is not possible as liposomal bupivacaine has a different consistency than control group drugs [28]. In other studies showing superior results with liposomal bupivacaine use, the medication was compared with a femoral nerve block or intrathecal morphine. However, in this study, liposomal bupivacaine infiltration was used as a part of multimodal analgesia protocol along with a continuous femoral nerve block [29] [30]. Since this is a placebo-controlled trial, it is more sensitive to small differences in pain scores between liposomal bupivacaine and bupivacaine $\mathrm{HCl}$, specifically in the initial postoperative period. In this study, the four surgeons performing periarticular injections agreed on injection technique for uniformity. To the best of our knowledge, this is only study comparing liposomal bupivacaine injection with placebo in a multimodal postoperative pain control protocol after TKA.

The biggest limitation of this study is that it is a single center trial with a small sample size. However, an attempt to compensate for the small sample size was made by considering significant improvement only if there was a pain score difference of three. Another shortcoming of the study was inability of the patients to differentiate between anterior and posterior pain particularly while moving the knee. Since this study, we have learned that the method of infiltration by the surgeon makes a difference in the pain relief obtained with liposomal bupivacaine.

\section{Conclusion}

Liposomal bupivacaine seems promising for extended duration pain control in local infiltration as part of multimodal approach for acute pain after TKA. In this study, we demonstrated significant improvement in pain scores without any significant differences in opioid requirement for acute postoperative pain control in liposomal bupivacaine group compared to the placebo group. Larger sample size may reveal significant differences in opioid requirements.

\section{References}

[1] Warfield, C.A. and Kahn, C.H. (1995) Acute Pain Management. Programs in U.S. Hospitals and Experiences and Attitudes among U.S. Adults. Anesthesiology, 83, 1090-1094. http://www.ncbi.nlm.nih.gov/pubmed/7486160 https://doi.org/10.1097/00000542-199511000-00023

[2] Wylde, V., Rooker, J., Halliday, L. and Blom, A. (2011) Acute Postoperative Pain at Rest after Hip and Knee Arthroplasty: Severity, Sensory Qualities and Impact on Sleep. Orthopaedics \& Traumatology, Surgery \& Research, 97, 139-144. http://www.ncbi.nlm.nih.gov/pubmed/21388906 https://doi.org/10.1016/j.otsr.2010.12.003

[3] Weinstein, A.M., Rome, B.N., Reichmann, W.M., Collins, J.E., Burbine, S.A., Thornhill, T.S., Wright, J., Katz, J.N. and Losina, E. (2013) Estimating the Burden of Total Knee Replacement in the United States. Journal of Bone and Joint Surgery (American Volume), 95, 385-392. 
http://www.ncbi.nlm.nih.gov/pubmed/23344005

[4] Maradit Kremers, H., Larson, D.R., Crowson, C.S., Kremers, W.K., Washington, R.E., Steiner, C.A., Jiranek, W.A. and Berry, D.J. (2015) Prevalence of Total Hip and Knee Replacement in the United States. Journal of Bone and Joint Surgery (American Volume), 97, 1386-1397.

http://www.ncbi.nlm.nih.gov/pubmed/26333733

[5] Losina, E., Thornhill, T.S., Rome, B.N., Wright, J., and Katz, J.N. (2012) The Dramatic Increase in Total Knee Replacement Utilization Rates in the United States Cannot Be Fully Explained by Growth in Population Size and the Obesity Epidemic. Journal of Bone and Joint Surgery (American Volume), 94, 201-207. http://www.ncbi.nlm.nih.gov/pubmed/22298051

[6] American Society of Anesthesiologists Task Force on Acute Pain Management (2012) Practice Guidelines for Acute Pain Management in the Perioperative Setting: An Updated Report by the American Society of Anesthesiologists Task Force on Acute Pain Management. Anesthesiology, 116, 248-273. http://www.ncbi.nlm.nih.gov/pubmed/22227789

[7] Curtiss, C.P. (2001) JCAHO: Meeting the Standards for Pain Management. Orthopaedic Nursing, 20, 27-30, 41. http://www.ncbi.nlm.nih.gov/pubmed/12024631 https://doi.org/10.1097/00006416-200103000-00008

[8] Toftdahl, K., Nikolajsen, L., Haraldsted, V., Madsen, F., Tonnesen, E.K. and Soballe, K. (2007) Comparison of Peri- and Intraarticular Analgesia with Femoral Nerve Block after Total Knee Arthroplasty: A Randomized Clinical Trial. Acta Orthopaedica, 78, 172-179.

http://www.ncbi.nlm.nih.gov/pubmed/17464603 https://doi.org/10.1080/17453670710013645

[9] Buvanendran, A., Kroin, J.S., Tuman, K.J., Lubenow, T.R., Elmofty, D., Moric, M. and Rosenberg, A.G. (2003) Effects of Perioperative Administration of a Selective Cyclooxygenase 2 Inhibitor on Pain Management and Recovery of Function after Knee Replacement: A Randomized Controlled Trial. JAMA, 290, 2411-2418. http://www.ncbi.nlm.nih.gov/pubmed/14612477 https://doi.org/10.1001/jama.290.18.2411

[10] Essving, P., Axelsson, K., Aberg, E., Spannar, H., Gupta, A. and Lundin, A. (2011) Local Infiltration Analgesia versus Intrathecal Morphine for Postoperative Pain Management after Total Knee Arthroplasty: A Randomized Controlled Trial. Anesthesia and Analgesia, 113, 926-933.

http://www.ncbi.nlm.nih.gov/pubmed/21821506 https://doi.org/10.1213/ANE.0b013e3182288deb

[11] Nagafuchi, M., Sato, T., Sakuma, T., Uematsu, A., Hayashi, H., Tanikawa, H., Okuma, K., Hashiuchi, A., Oshida, J. and Morisaki, H. (2015) Femoral Nerve Block-Sciatic Nerve Block vs. Femoral Nerve Block-Local Infiltration Analgesia for Total Knee Arthroplasty: A Randomized Controlled Trial. BMC Anesthesiology, 15, 182.

http://www.ncbi.nlm.nih.gov/pubmed/26669859 https://doi.org/10.1186/s12871-015-0160-3

[12] Apfel, C., Jahr, J.R., Kelly, C.L., Ang, R.Y. and Oderda, G.M. (2015) Effect of i.v. Acetaminophen on Total Hip or Knee Replacement Surgery: A Case-Matched Evaluation of a National Patient Database. American Journal of Health-System Pharmacy, 72, 1961-1968. http://www.ncbi.nlm.nih.gov/pubmed/26541951

[13] Lamplot, J.D., Wagner, E.R. and Manning, D.W. (2014) Multimodal Pain Management in Total Knee Arthroplasty: A Prospective Randomized Controlled Trial. 
Journal of Arthroplasty, 29, 329-334.

http://www.ncbi.nlm.nih.gov/pubmed/23850410

https://doi.org/10.1016/j.arth.2013.06.005

[14] Wheeler, M., Oderda, G.M., Ashburn, M.A. and Lipman, A.G. (2002) Adverse Events Associated with Postoperative Opioid Analgesia: A Systematic Review. Journal of Pain, 3,159-180. http://www.ncbi.nlm.nih.gov/pubmed/14622770 https://doi.org/10.1054/jpai.2002.123652

[15] Pizzi, L.T., Toner, R., Foley, K., Thomson, E., Chow, W., Kim, M., Couto, J., Royo, M. and Viscusi, E. (2012) Relationship between Potential Opioid-Related Adverse Effects and Hospital Length of Stay in Patients Receiving Opioids after Orthopedic Surgery. Pharmacotherapy, 32, 502-514.

http://www.ncbi.nlm.nih.gov/pubmed/22570188

https://doi.org/10.1002/j.1875-9114.2012.01101.x

[16] Feierman, D.E., Kronenfeld, M., Gupta, P.M., Younger, N. and Logvinskiy, E. (2014) Liposomal Bupivacaine Infiltration into the Transversus Abdominis Plane for Postsurgical Analgesia in Open Abdominal Umbilical Hernia Repair: Results from a Cohort of 13 Patients. Journal of Pain Research, 7, 477-482.

http://www.ncbi.nlm.nih.gov/pubmed/25170277 https://doi.org/10.2147/JPR.S65151

[17] Pereira, J., Lawlor, P., Vigano, A., Dorgan, M. and Bruera, E. (2001) Equianalgesic Dose Ratios for Opioids. A Critical Review and Proposals for Long-Term Dosing. Journal of Pain and Symptom Management, 22, 672-687. http://www.ncbi.nlm.nih.gov/pubmed/11495714 https://doi.org/10.1016/S0885-3924(01)00294-9

[18] Moiniche, S., Mikkelsen, S., Wetterslev, J. and Dahl, J.B. (1998) A Qualitative Systematic Review of Incisional Local Anaesthesia for Postoperative Pain Relief after Abdominal Operations. British Journal of Anaesthesia, 81, 377-383.

http://www.ncbi.nlm.nih.gov/pubmed/9861124 https://doi.org/10.1093/bja/81.3.377

[19] Haas, E., Onel, E., Miller, H., Ragupathi, M. and White, P.F. (2012) A Double-Blind, Randomized, Active-Controlled Study for Post-Hemorrhoidectomy Pain Management with Liposome Bupivacaine, a Novel Local Analgesic Formulation. American Surgeon, 78, 574-581. http://www.ncbi.nlm.nih.gov/pubmed/22546131

[20] Schroer, W.C., Diesfeld, P.G., LeMarr, A.R., Morton, D.J. and Reedy, M.E. (2015) Does Extended-Release Liposomal Bupivacaine Better Control Pain than Bupivacaine after Total Knee Arthroplasty (TKA)? A Prospective, Randomized Clinical Trial. Journal of Arthroplasty, 30, 64-67.

http://www.ncbi.nlm.nih.gov/pubmed/26117072

https://doi.org/10.1016/j.arth.2015.01.059

[21] Alijanipour, P., Tan, T.L., Matthews, C.N., Viola, J.R., Purtill, J.J., Rothman, R.H., Parvizi, J. and Austin, M.S. (2017) Periarticular Injection of Liposomal Bupivacaine Offers No Benefit over Standard Bupivacaine in Total Knee Arthroplasty: A Prospective, Randomized, Controlled Trial. Journal of Arthroplasty, 32, 628-634.

http://www.ncbi.nlm.nih.gov/pubmed/27667533 https://doi.org/10.1016/j.arth.2016.07.023

[22] Bramlett, K., Onel, E., Viscusi, E.R. and Jones, K. (2012) A Randomized, Double-Blind, Dose-Ranging Study Comparing Wound Infiltration of DepoFoam Bupivacaine, an Extended-Release Liposomal Bupivacaine, to Bupivacaine $\mathrm{HCl}$ for Postsurgical Analgesia in Total Knee Arthroplasty. The Knee, 19, 530-536.

http://www.ncbi.nlm.nih.gov/pubmed/22285545 
https://doi.org/10.1016/j.knee.2011.12.004

[23] Collis, P.N., Hunter, A.M., Vaughn, M.D., Carreon, L.Y., Huang, J. and Malkani, A.L. (2016) Periarticular Injection after Total Knee Arthroplasty Using Liposomal Bupivacaine vs a Modified Ranawat Suspension: A Prospective, Randomized Study. Journal of Arthroplasty, 31, 633-636.

http://www.ncbi.nlm.nih.gov/pubmed/26482684

https://doi.org/10.1016/j.arth.2015.09.025

[24] Schwarzkopf, R., Drexler, M., Ma, M.W., Schultz, V.M., Le, K.T., Rutenberg, T.F. and Rinehart, J.B. (2016) Is There a Benefit for Liposomal Bupivacaine Compared to a Traditional Periarticular Injection in Total Knee Arthroplasty Patients with a History of Chronic Opioid Use? Journal of Arthroplasty, 31, 1702-1705.

http://www.ncbi.nlm.nih.gov/pubmed/26897490

https://doi.org/10.1016/j.arth.2016.01.037

[25] Bagsby, D.T., Ireland, P.H. and Meneghini, R.M. (2014) Liposomal Bupivacaine versus Traditional Periarticular Injection for Pain Control after Total Knee Arthroplasty. Journal of Arthroplasty, 29, 1687-1690.

http://www.ncbi.nlm.nih.gov/pubmed/24793570 https://doi.org/10.1016/j.arth.2014.03.034

[26] Kirkness, C.S., Asche, C.V., Ren, J., Kim, M. and Rainville, E.C. (2016) Cost-Benefit Evaluation of Liposomal Bupivacaine in the Management of Patients Undergoing Total Knee Arthroplasty. American Journal of Health-System Pharmacy, 73, e247-e254. http://www.ncbi.nlm.nih.gov/pubmed/27099332 https://doi.org/10.2146/ajhp150332

[27] Cherian, J.J., Muzaffar, A., Barrington, J.W., Elmallah, R.D., Chughtai, M., Mistry, J.B. and Mont, M.A. (2016) Liposomal Bupivacaine in Total Knee Arthroplasty for Better Postoperative Analgesic Outcome and Economic Benefits. Journal of Knee Surgery, 29, 180-187. http://www.ncbi.nlm.nih.gov/pubmed/26713595 https://doi.org/10.1055/s-0035-1570369

[28] Jain, R.K., Porat, M.D., Klingenstein, G.G., Reid, J.J., Post, R.E. and Schoifet, S.D. (2016) The AAHKS Clinical Research Award: Liposomal Bupivacaine and Periarticular Injection Are Not Superior to Single-Shot Intra-articular Injection for Pain Control in Total Knee Arthroplasty. Journal of Arthroplasty, 31, 22-25.

http://www.ncbi.nlm.nih.gov/pubmed/27113945

https://doi.org/10.1016/j.arth.2016.03.036

[29] Broome, C.B. and Burnikel, B. (2014) Novel Strategies to Improve Early Outcomes Following Total Knee Arthroplasty: A Case Control Study of Intra Articular Injection versus Femoral Nerve Block. International Orthopaedics, 38, 2087-2089.

http://www.ncbi.nlm.nih.gov/pubmed/24938586

https://doi.org/10.1007/s00264-014-2392-0

[30] Cien, A.J., Penny, P.C., Horn, B.J., Popovich, J.M. and Taunt, C.J. (2015) Comparison between Liposomal Bupivacaine and Femoral Nerve Block in Patients Undergoing Primary Total Knee Arthroplasty. Journal of Surgical Orthopaedic Advances, 24, 225-229. http://www.ncbi.nlm.nih.gov/pubmed/26731385 